\title{
Depression in Orthodontic Patients
}

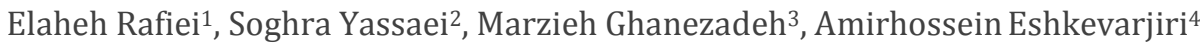

\begin{abstract}
${ }^{1}$ Department of Orthodontics, Shahid Sadoughi University of Medical Sciences, Yazd, Iran. ${ }^{2}$ Department of Orthodontics, Shahid Sadoughi University of Medical Sciences, Yazd, Iran. ${ }^{3}$ Shahid Sadoughi University of Medical Sciences, Yazd, Iran. ${ }^{4}$ Shahid Sadoughi University of Medical Sciences, Yazd, Iran.
\end{abstract}

\section{ABSTRACT}

\section{BACKGROUND}

This study aimed to determine the prevalence of depression in a group of patients referred for orthodontic treatments which can be helpful in the better and more successful treatment planning.

\section{METHODS}

Beck's depression inventory was administered to 350 patients in the age group of 16 - 29 years who were referred to the Department of Orthodontics. Each patient was examined by the orthodontist for type of malocclusion classifications and finally the relation between the severity of the depression and the type of malocclusion was determined. SPSS software was used for analysing the data using the chi-square, oneway Anova, t-test and Tukey's test. The significance was set at 0.05 .

\section{RESULTS}

Prevalence of depression among class I, II, and III patients was $22.4 \%, 32.7 \%$ and $39.6 \%$, respectively. There was no significant relation between gender, marital status, educational status, and depression $(\mathrm{p}>0.05)$. However, there was a significant relation between types of malocclusion and depression $(\mathrm{p}<0.05)$. The relation between class I and class III malocclusions and depression was significantly different, with the highest depression prevalence in Class III patients ( $p=0.003)$.

\section{CONCLUSIONS}

There is a relatively high prevalence of depression among orthodontic patients, especially among patients with Angle's class III malocclusion.

\section{KEY WORDS}

Prevalence, Depression, Orthodontics, Malocclusion
Corresponding Author:

Dr. Elaheh Rafiei,

Shahid Sadoughi University of Medical

Sciences, Dental School, Dahe Fajr Blvd., Yazd, Iran.

E-mail: elahe_rafiei88@yahoo.com

DOI: $10.14260 /$ jemds/2020/630

How to Cite This Article:

Rafiei E, Yassaei S, Ghanezadeh M, et al. Depression in orthodontics, patients. J Evolution Med Dent Sci 2020;9(39):28802883, DOI: $10.14260 /$ jemds $/ 2020 / 630$

\footnotetext{
Submission 21-06-2020,

Peer Review 18-08-2020,

Acceptance 24-08-2020,

Published 28-09-2020.
}

Copyright (C) 2020 Elaheh Rafiei et al. This is an open access article distributed under Creative Commons Attribution License [Attribution 4.0 International (CC BY 4.0)] 


\section{BACKGROUND}

In every society, paying attention to the physical, mental, social, and cultural health of individuals and providing the necessary conditions for an active and healthy life ensures the health of that community for years to come. ${ }^{1}$ today, the World Health Organization has expressed mental health as one of the most critical health problems around the world. ${ }^{2}$

The evidence suggests that depression is the most common psychological problem in today's life, and estimations show more than 20 percent of the public society suffers from emotional distress and depression. ${ }^{3}$

Malocclusion is referred to as the abnormal status of the teeth or the skeletal position of maxilla and mandible with each other. ${ }^{4}$ It has been found that people are depressed due to the irregularity of their teeth and consequently, their unwillingness to laugh, and one of the best ways to solve this problem is orthodontic treatment. ${ }^{5}$ Orthodontic treatments may focus only on correcting the teeth or changing the pattern and direction of maxillary and mandibular growth (orthosurgery therapies). ${ }^{6}$

The study of Zhang et $\mathrm{al}^{7}{ }^{7}$ on personality and psychological aspects of individuals stated that adults with malocclusion have higher scores of mental disorders than those with natural occlusion and they also stated psychological tests can well determine qualitative and quantitative changes in diagnosis and treatment of patients so this can lead to better understanding of the patient's concerns and demands.

Macias Gago et al, ${ }^{8}$ reported the increase in the malocclusion severity creates less physical attraction in individuals. Another research conducted by Philips et al, ${ }^{9}$ stated that psychological study of the patients before starting the orthodontic treatment is better than studying the patients who have started orthodontic treatment. Early diagnosis of depressive sources and attempting to modify them can have a significant impact on the mental health of orthodontic patients and subsequently in the community and can lead to satisfaction and ultimately confidence in them. ${ }^{5}$

The best results of orthodontic treatment are achieved when the underlying psychological problem is diagnosed, and the patient's expectations of orthodontics are determined. ${ }^{10}$ Moreover, it is necessary that the use of orthodontic appliances be carefully considered and before using them, their advantages and disadvantages must be assessed in order not to have a negative effect on the psychological and mental state of the patient. 11

So despite the relatively large studies that have been done in the field of depression, information about the prevalence of depression in the group of patients, especially the prevalence of this disorder in patients who want to do orthodontics treatment in Iran, is not much available. Considering the different probability of depressive resources and mental health of orthodontic patients in the Iranian community, this research designed to determine depression's prevalence in the patients aged between 16-29 years referred for orthodontic treatments in the city of Yazd in Iran in 2016-2017.

\section{METHODS}

This descriptive cross sectional study was reviewed and approved by the Research Ethics Committee under code "IR. SSU. REC. 13950180". Considering the sample size formula-

$$
\left(n=\frac{Z_{1-\frac{\alpha}{2}}^{2}{ }^{P(1-P)}}{d^{2}}\right)
$$

Previous prevalence of depression in orthodontic patients (P) was $18 \%$, taking into account $\alpha=0.05$ and $d=0.04$, the sample size was calculated $n=350$ samples. The statistical population of this study consisted of patients aged 16 to 29 years seeking orthodontic treatment referred to the Department of Orthodontics between 2016 and 2018. A list of 1100 patients was arranged and using simple random sampling, 350 of them were selected and then informed consent for participating in the study was taken. Inclusion criteria included patient satisfaction with participation in the study, age group of 16 to 29 years, and need for orthodontic treatment. Exclusion criteria included patients who had histories such as systemic disease, any mental disorder, depression, antidepressant and pregnancy medication use. Also, unfinished questionnaires were excluded. In this study, the data collection tool was a two-part questionnaire. The first part of the questionnaire was related to the demographic data (gender, marital status, educational status) of the patients, while the second section was related to Beck's Depression Inventory (BDI). The questionnaire included 21 questions assessing the severity of depression symptoms. There are four items for each of the questions from zero (absence) to three (severe), and the total score of the questionnaire includes a range from zero to 63 . The depression assessment criterion was based on the Likert Scale as following: 0-16 ratings indicate the absence of depression, 17-32 is mild depression, 33-47 is moderate depression and 48-63 indicates severe depression. An orthodontist examined each patient for the type of malocclusion classifications based on Angle's classification (187 class I malocclusion, 110 class II malocclusion and 53 class III malocclusion). Finally the relation between the severity of the depression and the type of malocclusion was determined. After data collection, they were entered into SPSS software (v. 23; IBM, NY, USA). This software was used for analyzing the data using a parametric t-test, ChiSquare, Tukey, and one-way ANOVA tests. The Tukey's significant difference test was used to evaluate the significant groups. The significance level was set at 0.05 .

\section{RESULTS}

Prevalence of depression according to gender, marital status, and the educational state of the patients is shown in table (1). A total of 350 patients completed the questionnaire that 29.4 $\%$ of the samples were male, $70.6 \%$ female, $26 \%$ were married, $74 \%$ single, $38.3 \%$ had a bachelor's degree, and 27.4 $\%$ had a lower high school diploma (Table 1 ). 


\begin{tabular}{|c|c|c|c|c|c|}
\hline Variables & $\begin{array}{l}\text { Total } \\
(350)\end{array}$ & $\begin{array}{l}\text { Patients } \\
\text { with no } \\
\text { Depression } \\
\text { (251) }\end{array}$ & $\begin{array}{c}\text { Patients } \\
\text { with Mild } \\
\text { Depression } \\
\text { (87) }\end{array}$ & $\begin{array}{l}\text { Patients with } \\
\text { Moderate } \\
\text { Depression } \\
\text { (12) }\end{array}$ & $\begin{array}{c}P \\
\text { Value }\end{array}$ \\
\hline \multicolumn{6}{|c|}{ (251) Gender $(01)$} \\
\hline Male & $\begin{array}{c}103 \\
(29.4 \%)\end{array}$ & $\begin{array}{c}79 \\
(76.7 \%)\end{array}$ & $\begin{array}{c}19 \\
(18.4 \%)\end{array}$ & $\begin{array}{c}5 \\
(7.9 \%)\end{array}$ & \multirow{2}{*}{0.151} \\
\hline Female & $\begin{array}{c}247 \\
(70.6 \%)\end{array}$ & $\begin{array}{c}172 \\
\text { (69.6\%) } \\
\text { Marital }\end{array}$ & $\begin{array}{c}68 \\
(27.5 \%)\end{array}$ & $\begin{array}{c}7 \\
(2.8 \%)\end{array}$ & \\
\hline Single & $\begin{array}{c}91 \\
(26 \%)\end{array}$ & $\begin{array}{c}185 \\
(71.4 \%)\end{array}$ & $\begin{array}{c}65 \\
(25.1 \%)\end{array}$ & $\begin{array}{c}9 \\
(3.5 \%)\end{array}$ & \multirow[b]{2}{*}{0.98} \\
\hline Married & $\begin{array}{c}259 \\
(74 \%)\end{array}$ & $\begin{array}{c}66 \\
(72.5 \%) \\
\text { Educatiol }\end{array}$ & $\begin{array}{c}22 \\
(24.2 \%)\end{array}$ & $\begin{array}{c}3 \\
3 \\
(3.3 \%)\end{array}$ & \\
\hline Under grad. & $\begin{array}{c}96 \\
(27.4 \%)\end{array}$ & $\begin{array}{c}64 \\
(66.7 \%)\end{array}$ & $\begin{array}{c}28 \\
(29.2 \%)\end{array}$ & $\begin{array}{c}4 \\
(4.2 \%)\end{array}$ & \multirow{5}{*}{0.642} \\
\hline $\begin{array}{l}\text { High school } \\
\text { diploma }\end{array}$ & $\begin{array}{c}91 \\
(26 \%)\end{array}$ & $\begin{array}{c}64 \\
(70.3 \%)\end{array}$ & $\begin{array}{c}24 \\
(26.4 \%)\end{array}$ & $\begin{array}{c}3 \\
(3.3 \%)\end{array}$ & \\
\hline $\begin{array}{l}\text { apsoma } \\
\text { Associate }\end{array}$ & & $\begin{array}{c}(70.3 \%) \\
19\end{array}$ & & & \\
\hline & $(8.3 \%)$ & & $(31 \%)$ & $(3.4 \%)$ & \\
\hline $\begin{array}{l}\text { Bachelor and } \\
\text { higher }\end{array}$ & $\begin{array}{c}134 \\
(38.3 \%)\end{array}$ & $\begin{array}{c}104 \\
(77.6 \%)\end{array}$ & $\begin{array}{c}26 \\
(19.4 \%)\end{array}$ & $\begin{array}{c}4 \\
(3 \%)\end{array}$ & \\
\hline nilguer & $(30.3 \%)$ & $(77.6 \%)$ & $(19.4 \%)$ & $(3 \%)$ & \\
\hline
\end{tabular}

Of the 350 patients, 99 (28.3\%) were screened positive for depression. From these 99 patients, 87 (24.85\%) were suffering from mild depression, and $12(3.42 \%)$ were suffering from moderate depression. The prevalence of depression according to types of malocclusion is shown in table 2 .

\begin{tabular}{|c|c|c|c|c|c|}
\hline $\begin{array}{l}\frac{y}{20} \\
\frac{\pi}{\pi / \pi} \\
\frac{\pi}{2}\end{array}$ & 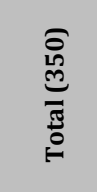 & 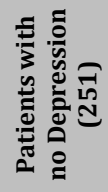 & 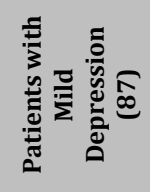 & 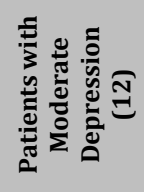 & $\frac{\varrho}{\frac{0}{\pi}}$ \\
\hline \multicolumn{6}{|c|}{ Malocclusion } \\
\hline Class I & $\begin{array}{c}187 \\
(53.4 \%)\end{array}$ & $\begin{array}{c}145 \\
775 \%\end{array}$ & 38 & $\begin{array}{c}4 \\
4\end{array}$ & \multirow{4}{*}{$0.017^{*}$} \\
\hline \multirow{3}{*}{ Class II } & 110 & 74 & 33 & 3 & \\
\hline & (31.4\%) & $(67.3 \%)$ & $(30 \%)$ & $(2.7 \%)$ & \\
\hline & $(15.1 \%)$ & $(60.4 \%)$ & (30.2\%) & $(9.4 \%)$ & \\
\hline \multicolumn{6}{|c|}{$\begin{array}{l}\text { Table 2. Prevalence of Depression among Orthodontic Patients } \\
\text { According to Different Types of Malocclusion }\end{array}$} \\
\hline
\end{tabular}

There was no significant difference between depression and gender, marital status, and educational state of patients ( $p>0.05)$. However, the relation between depression severity and the type of malocclusion was significant $(\mathrm{p}<0.05)$. The depression prevalence in class III malocclusion was significantly more than class I malocclusion $(p=0.003)$ (Table 3).

\begin{tabular}{|cccccc|}
\hline Variable & Malocclusions & $\begin{array}{c}\text { Mean } \\
\text { difference }\end{array}$ & Std. Error & P Value \\
& Class I I Class II & -1.67 & 1.03 & 0.024 \\
& Class III & -4.40 & 1.34 & $0.003^{*}$ \\
depression & Class II & Class I & 1.67 & 1.03 & 0.024 \\
& & Class III & -2.72 & 1.44 & 0.142 \\
& Class III & Class I & 4.4 & 1.34 & $0.003^{*}$ \\
& Class II & 2.72 & 1.44 & 0.142 \\
\hline \multicolumn{5}{c}{ Table 3. Post Hoc Tukey Test Results in } \\
Different Types of Malocclusion \\
\hline Note: $p$ value<0.05 is marked with asterisk (*). Std. Error: standard deviation Error \\
\hline \multicolumn{5}{c}{}
\end{tabular}

\section{DISCUSSION}

This research was designed to determine the prevalence of depression in the patients aged between 16-29 years referred for orthodontic treatments. It is hoped that findings from this study would help to increase the awareness of orthodontists about depression's prevalence in patients with malocclusion and the method of identifying the patient's underlying problem, which can be helpful in the better and more successful treatment plan.

Beck reported the reliability of beck's questionnaire 0.93, and Williams stated that its reliability was 0.90 , and its retest reliability was 0.75 .12 Beck's inventory validity has been reported high and varying between 0.70-0.90 in other studies, including Vahabzadeh's study in 1973, Partovi in 1975, and Chegini in 2002.13,14 In the current study, the prevalence of depression among the orthodontic patients has been reported 28.3\%; and depression's prevalence in the patients with class I, II, and III malocclusions is $22.4 \%, 32.7 \%$, and $39.6 \%$, respectively. The study of Takatsuji et al. ${ }^{15}$ emphasizes that among the psychological disorders in patients with malocclusion, depression has the highest prevalence. Also in the study of Burden et al, ${ }^{9}$ the rate of depression and the other psychological disorders assessed by CDI and BDI questionnaires in the patients of classes II and III have been reported $27 \%$ and $25 \%$, respectively. In 2014, the study performed by Rashid et al, 16 on the orthodontic patients referring to the tertiary care hospital in Pakistan, showed a $31.64 \%$ prevalence of depression. In another study conducted on a Chinese population referring for orthodontic treatment, the depression rate has been reported $24.71 \% .{ }^{17}$ The results of the studies indicate a difference in the prevalence of malocclusion in various geographical areas and different cities; these differences are probably due to the ethnic, racial, and cultural differences in different climates and societies. The current study shows that the prevalence of depression in the orthodontic patients of Iranian society is slightly higher than those of Irish and Chinese communities.

Another finding from our study indicated that the prevalence of depression in patients with different malocclusions was significantly different, so that the prevalence of depression in class III patients was more than other malocclusions. The present study also demonstrated the patients with class I malocclusion had the least prevalence of depression; this suggests that there is a relation between the types of malocclusion and depression. The study of Takatsuji ET al. ${ }^{15}$ also showed that depression's prevalence in class III malocclusion patients was higher than those of class I and II patients. This study was also consistent with Klima et al. ${ }^{18}$ The reason for the higher prevalence of depression among patients with class III malocclusion can be the poor masticatory efficiency and ability compared to the patients with class II or I malocclusions and the fact that patients with class III malocclusion may distort the consonants $\mathrm{Zh} \mathrm{/} \mathrm{Sh} \mathrm{/} \mathrm{Z} \mathrm{/} \mathrm{Ch}$ which can lead to speech problems. ${ }^{19}$ Also, the patient's facial appearance with Class III malocclusion can be less acceptable in different communities. These all demonstrate the low quality of life in Class III patients, which can lead to low selfesteem and depression. The findings of Zhang et al, ${ }^{7}$ about the personality and psychological aspects suggest that adults with class I, II, and III malocclusion have higher scores of psychological disorders compared to the patients with normal occlusion, however patients with class II malocclusion scored higher on psychoticism. This can indicate the acceptance of Class III patients in the Chinese society as the prevalence of class III malocclusion is higher in Chinese community. ${ }^{20}$ According to the present study, the rate of depression in women has been reported more than men; however, this was 
not significantly different. In the study of Burden $\mathrm{ET}^{\mathrm{a}}{ }^{9}$ about two-third of the referring patients were female that shows women are more eager to correct the class II and III malocclusions. Also, in the current study, $70.6 \%$ of the patients were female. This finding can confirm women pay more attention to their facial appearance. Other study emphasized that compared to men, women are more likely to show depression symptoms and psychological diseases. ${ }^{21}$ Restrictions on sampling and limited number of samples to select as the control group were the most important limitations of this study. More accurate and reliable results could be obtained if more studies were conducted with larger sample size and presence of a control group.

\section{CONCLUSIONS}

There is a relatively high prevalence of depression among orthodontic patients, especially the patients with Angle's class III malocclusion. Orthodontists should be aware of the prevalence of depression in patients referred for orthodontic treatments, and identifying them can lead to a better patient management. In this way, many problems arising from abnormal psychological problems and behaviours can be minimized.

Financial or Other Competing Interests: None.

\section{REFERENCES}

[1] Vinod K, Reddy YG, Reddy VP, et al. Orthodonticperiodontics interdisciplinary approach. J Indian Soc Periodontol 2012;16(1):11-5.

[2] Davey CG, Yücel M, Allen NB. The emergence of depression in adolescence: development of the prefrontal cortex and the representation of reward. Neurosci Biobehav Rev 2008;32(1):1-19.

[3] Vaziri S, Dehestani M, Framarzi HSG. Surveying depression in asthmatic patients. Medical Science Journal of Islamic Azad Univesity-Tehran Medical Branch 2007;17(3):161-4.

[4] Manjula W, Sukumar M, Kishorekumar S, et al. Smile: a review. J Pharm Bioallied Sci 2015;7(Suppl 1):S271-5.

[5] Kang JM, Kang KH. Effect of malocclusion or orthodontic treatment on oral health-related quality of life in adults. Korean J Orthod 2014;44(6):304-11.

[6] Sam K, Rabie AB, King NM. Orthodontic intrusion of periodontally involved teeth. J Clin Orthod 2001;35(5):325-30.
[7] Zhang L, Liu X, Zheng GJ, et al. Eysenck personality and psychosocial status of adult patients with malocclusion. Asian Pac J Trop Med 2012;5(2):151-6.

[8] Macías Gago AB, Romero Maroto M, Crego A. The perception of facial aesthetics in a young Spanish population. Eur J Orthod 2012;34(3):335-9.

[9] Burden DJ, Hunt O, Johnston CD, et al. Psychological status of patients referred for orthognathic correction of skeletal II and III discrepancies. Angle Orthod 2010;80(1):43-8.

[10] Yassaei S, Moghadam MG, Aghili H, et al. Body dysmorphic disorder in Iranian orthodontic patients. Acta Med Iran 2014;52(6):454-7.

[11] Topcuoglu T, Yildirim O, Birlik M, et al. The effect of orthodontic extraoral appliances on depression and the anxiety levels of patients and parents. Niger J Clin Pract 2014;17(1):81-5.

[12] Lee EH, Lee SJ, Hwang ST, et al. Reliability and validity of the Beck Depression Inventory-II among Korean adolescents. Psychiatry Investigation 2017;14(1):30-6.

[13] Beck AT, Steer RA, Carbin MG. Psychometric properties of the beck depression inventory: twenty-five years of evaluation. Clinical Psychology Review 1988;8(1):77100.

[14] Azkhosh M. Application of psychological tests and diagnosis. $3^{\text {rd }}$ edn. Tehran: Psychology 2008:224-6.

[15] Takatsuji H, Kobayashi T, Kojima T, et al. Effects of orthognathic surgery on psychological status of patients with jaw deformities. Int J Oral Maxillofac Surg 2015;44(9):1125-30.

[16] Rashid H, Hussain SS. Prevalence of depression, anxiety and stress among orthodontics patients visiting a tertiary care hospital, Pakistan. Int J Dent Clin 2014;6(1).

[17] Luo H, Feng YZ, Xu XF, et al. Correlation between anxiety, depression and pefectionistic tendencies in patients before orthodontic treatment. Shanghai Kou Qiang Yi Xue 2014;23(5):609-13.

[18] Klima RJ, Wittemann JK, McIver JE. Body image, selfconcept, and the orthodontic patient. Am J Orthod 1979;75(5):507-16.

[19] Zhang M, McGrath C, Hägg U. The impact of malocclusion and its treatment on quality of life: a literature review. Int J Paediatr Dent 2006;16(6):381-7.

[20] Chew MT. Soft and hard tissue changes after bimaxillary surgery in Chinese Class III patients. Angle Orthod 2005;75(6):959-63.

[21] Minghelli B, Morgado M, Caro T. Association of temporomandibular disorder symptoms with anxiety and depression in Portuguese college students. J Oral Sci 2014;56(2):127-33. 